\title{
Control of Temperature and Aluminum Fluoride Concentration Based on Model Prediction in Aluminum Electrolysis
}

\author{
Zeng Shuiping, Wang Shasha, and Qu Yaxing \\ North China University of Technology, Beijing 100144, China \\ Correspondence should be addressed to Zeng Shuiping; zshp@ncut.edu.cn
}

Received 28 February 2014; Accepted 14 April 2014; Published 21 May 2014

Academic Editor: Peter Majewski

Copyright (c) 2014 Zeng Shuiping et al. This is an open access article distributed under the Creative Commons Attribution License, which permits unrestricted use, distribution, and reproduction in any medium, provided the original work is properly cited.

\begin{abstract}
The temperature and the aluminum fluoride $\left(\mathrm{AlF}_{3}\right)$ concentration of electrolyte greatly affect the current efficiency and energy consumption in aluminum electrolysis. This paper developed a new kind of algorithm to control the temperature and $\mathrm{AlF}_{3}$ concentration of electrolyte for $300 \mathrm{kA}$ prebake aluminum production cells by altering the setting cell voltage and the $\mathrm{AlF}_{3}$ adding rate. One is liquidus model which can be used to calculate $\mathrm{AlF}_{3}$ concentration of electrolyte by some technical parameters and target superheat and the other is the temperature models which can determine the required cell voltage by the technical parameters and target temperature. Consequently, the $\mathrm{AlF}_{3}$ addition rate can be decided by the $\mathrm{AlF}_{3}$ concentration. The temperature and $\mathrm{AlF}_{3}$ concentration of electrolyte in the production are measured and the differences between the measurement and the corresponding calculation are used as feedback to correct the model. The coefficients in the model are also revised according to the external conditions. This system has been used in an aluminum company for 2 years. Both the temperature and the $\mathrm{AlF}_{3}$ concentration of electrolyte can be controlled as required and the energy consumption of the aluminum production was much decreased.
\end{abstract}

\section{Introduction}

The control of aluminum reduction cells is very important to improve the economic index and has been given more and more attention recently. Because the current efficiency and the energy consumption of the process cannot be known within a short period of time, they are not suitable to be used as control parameters in the process control system. The temperature and $\mathrm{AlF}_{3}$ concentration of electrolyte are very important factors for aluminum production cells. Temperature should be kept in a reasonable range, usually $945-$ $955^{\circ} \mathrm{C}$ (degree Celsius). Industrial processes showed that if temperature is 10 degree higher than the required value, the current efficiency decreases by $2 \%$ and the energy consumption increases by $3 \%$ [1]. The $\mathrm{AlF}_{3}$ concentration of electrolyte is the most important factor affecting the superheat of the alumina reduction. The superheat can be taken as a comprehensive embodiment to the energy equilibrium and the material equilibrium. The suitable superheat should be kept to make the cell good operation because large superheat causes the cell ledge to melt and energy consumption to increase and low superheat causes $\mathrm{Al}_{2} \mathrm{O}_{3}$ to dissolve difficult and low stability of cells. Many researchers considered that superheat should be kept between 6 and $12^{\circ} \mathrm{C}$. If the superheat increases by $10^{\circ} \mathrm{C}$, the current efficiency would decrease $1.2-1.5 \%$ [2]. Because the superheat is calculated from cell temperature and crystallized temperature of the electrolyte, the superheat can be decided by the compounds of the electrolyte if the temperature does not change obviously. The concentration of $\mathrm{AlF}_{3}$ and $\mathrm{Al}_{2} \mathrm{O}_{3}$ in electrolyte usually changes faster than others with time. $\mathrm{Al}_{2} \mathrm{O}_{3}$ can be controlled automatically by the cell controller to be kept between 1.5 and $2.5 \%$ [2], so the concentration of $\mathrm{AlF}_{3}$ is a very important parameter to affect the superheat and should be controlled.

The industrial aluminum production is a dynamic process which has some repeated operations, such as aluminum tapping once everyday, anode changed, and anode effect killing. It is well known that the aluminum production cell is a big delay, multivariety, nonlinear process and it is difficult to derive a mathematical model theoretically to describe the procedure. Till now the control of temperature and liquidus is based on the experience from the operators although some models are introduced in some papers $[3,4]$. The fuzzy control was used in some factories in recent years, which 
made some progresses, but there are some defaults for the aluminum production. Once the rule base was constructed, they would work a long period of time and cannot be revised easily. It is unfortunate that the fuzzy control does not use the feedback to correct the control output and the previous experience cannot well suit the next stage in some cases [5].

\section{Calculation of Temperature and Concentration of $\mathbf{A l F}_{3}$}

2.1. Model for the Temperature with Some Technical Parameters. The temperature of electrolyte depended on the heat balance in aluminum electrolysis, which is very complex because the heat loss cannot be calculated precisely. Some papers discussed problem [6], but only the percentage of the heat flow of some areas was shown in picture so it is impossible to give a precise equation to calculate the temperature. It is fortunate that we have a lot of data sampled online or measured in site, which were saved in the database and can be used to analyze the behavior of aluminum production $[7,8]$.

Usually operators control the cell temperature in practice by changing the cell voltage, the addition amount of $\mathrm{AlF}_{3}$, and the aluminum level. Here we also use the three parameters to calculate the cell temperature. Therefore, the cell voltage, aluminum level, and fluoride addition were selected as varieties to build an equation by multiregression method. Theoretic analysis and operators' experiences in the industrial process showed that the cell voltage increase results in cell temperature increase, the fluoride addition results in decrease of temperature, and the higher the aluminum level, the lower the temperature. The two power regressions were used in the equation because the higher power has little contribution to the process. The model type was set as follows:

$$
\Delta T=a \Delta V+b \Delta A+c \Delta F+c_{1} \Delta F^{2}+d T c+\text { Err. }
$$

The equation can be also expressed as

$$
\begin{aligned}
T(K) & -T(K-1) \\
= & a(V(K-1)-V K(-2)) \\
& +b(A(K-1)-A(K-2)) \\
& +c(F(K-1)-F(K-2)) \\
& +c 1(F(K-1)-F(K-2)) 2+d T c+\text { Err }
\end{aligned}
$$

where $T(K), T(K-1)$ is temperature $\left({ }^{\circ} \mathrm{C}\right)$ at time $k$ and $k-1$, respectively; $V(K), F(K)$ is cell voltage and fluoride addition weight, respectively, at $k ; A(K)$ is aluminum level at $k ; T c$ is atmosphere temperature; Err is error revision item; and $a, b$, $c, c_{1}$, and $d$ are coefficients.

The coefficients $\left(a, b, c, c_{1}\right.$, and $\left.d\right)$ were calculated from the historic data in database by means of multiregression. Err is the difference between the measured temperature and the calculated one. Here just $\Delta F$ was adopted as twice power because fluoride addition affects the temperature more complex than cell voltage and aluminum level. The cold material absorbs large amount of heat and the addition of $\mathrm{AlF}_{3}$ causes the ledge to melt, which causes the heat to be diffused faster.

The following is a temperature model built originally with historic data for one test cell:

$$
\begin{aligned}
T(K)-T(K-1)= & 0.113 \Delta V-0.653 \Delta F+0.012 \Delta F^{2} \\
& +0.062 \Delta A+0.011 T c+E_{0},
\end{aligned}
$$

where $E_{0}$ is error revision item; it is set to zero at first.

2.2. Model for the Concentration of $\mathrm{AlF}_{3} . \mathrm{AlF}_{3}$ is easy to vaporize at high temperature, so its concentration changes constantly by time. In the production process it must be added many times every day. As we know, the vaporization rate of $\mathrm{AlF}_{3}$ is mainly decided by temperature and concentration of $\mathrm{AlF}_{3}$. From the theory and practice, we know that the higher the temperature, the faster the vaporization and the higher the concentration, the faster the vaporization also. Because $\mathrm{AlF}_{3}$ is not free in the electrolyte and some of it combined with other substances, we considered the item of amount of added $\mathrm{AlF}_{3}$ in the calculation period. So, the vaporization rate of $\mathrm{AlF}_{3}$ can be expressed as

$$
W_{\text {vap AlF }}=\alpha(T-920)+\beta \mathrm{AlF}+\gamma W_{a \mathrm{AlF}}+C,
$$

where $W_{\text {vap AlF }}$ is vaporization rate of $\mathrm{AlF}_{3} ; T$ is temperature of electrolyte; $W_{a \mathrm{AlF}}$ is amount of added $\mathrm{AlF}_{3} ; \mathrm{AlF}$ concentration of free $\mathrm{AlF}_{3} ; \alpha, \beta$, and $\gamma$ are the coefficients; and $C$ is constant.

The constant $C$ is called correction item, which is set to zero at first time. In the control process it is calculated as follows:

$$
C=W_{a \mathrm{AlF}}-\left(\alpha T+\beta \mathrm{AlF}+\gamma W_{a \mathrm{AlF}}\right)-\frac{\left(W_{\mathrm{ele}} * \Delta \mathrm{AlF} / 100\right)}{N},
$$

where $W_{\text {ele }}$ is the weight of electrolyte, which is calculated from the height of electrolyte.

There is another question that the ledge of the cell absorbs some $\mathrm{AlF}_{3}$ or it melts with the change of temperature and the $\mathrm{AlF}_{3}$ concentration, which results in the AlF3 into the electrolyte. Also some added $\mathrm{AlF}_{3}$ cannot be dissolved quickly, which causes the time delay of the concentration of $\mathrm{AlF}_{3}$. This is a very complex problem, and it cannot be calculated precisely. Here it is supposed that undissolved $\mathrm{AlF}_{3}$ equals the dissolved $\mathrm{AlF}_{3}$ from solid phase. Therefore the $W_{\text {vap AlF }}$ can be calculated as follows:

$$
W_{\text {vap AlF }}=\sum W_{\text {vap AlF }} \Delta N
$$

where $W_{\text {vap AlF }}$ is the total vaporized weight of $\mathrm{AlF}_{3}$ during calculation period and $W_{a \mathrm{AlF}}$ in (4) and (5) can be read from the scale pan; $\Delta N$ is the time (days) corresponding to the $W_{\text {vap AlF }}$. Therefore the concentration of $\mathrm{AlF}_{3}$ can be got as follows:

$$
\mathrm{AlF} g=\frac{\left(W_{a \mathrm{AlF}_{3}}-W_{\text {vap } \mathrm{AlF}_{3}}\right) * n}{W_{\mathrm{ele}_{3}}}+\mathrm{AlF}
$$


where $N$ is days from last analysis to calculated time, $\mathrm{AlFg}$ and $\mathrm{AlF}$ are free concentration of $\mathrm{AlF}_{3}$ at the calculated time and at the time sampling for last analysis, respectively, $W_{a \mathrm{AlF}}$, $W_{\text {vap AlF }}$ are the weight of $\mathrm{AlF}_{3}$ added and vaporized during calculation periods, respectively, and $W_{\text {ele }}$ is average weight of the electrolyte from the calculation time to the sampling time for last analysis, which is related to electrolyte level.

\section{Calculation of $\mathbf{A l F}_{3}$ Addition Amount and the Set Voltage}

3.1. The Amount of $\mathrm{AlF}_{3}$ Addition. The main purpose to control $\mathrm{AlF}_{3}$ concentration is to keep the superheat in given range, so the needed $\mathrm{AlF}_{3}$ addition depended on the target temperature and superheat. Usually superheat is required between 6 and $12^{\circ} \mathrm{C}$. If the temperature was set at $950^{\circ} \mathrm{C}$, the liquidus should be $938-944^{\circ} \mathrm{C}$. Liquid temperature of the electrolyte is only determined by its composition. Asbjorn gave an empirical equation to calculate the liquid temperature from the electrolyte composition [9]. According to the liquidus measurement in the plant, the calculated value is rather bigger than the measured one, so we use an item to revise the equation. With added revised item it can be used to calculate the concentration of $\mathrm{AlF}_{3}$, which is [10]

$$
\begin{aligned}
& \text { Tcrs } \\
& =1011+0.50 \mathrm{AlF}-0.13 \mathrm{AlF}^{2.2}-\frac{3.45 \mathrm{CaF}}{1+0.0173 \mathrm{CaF}} \\
& +0.124 * \mathrm{AlF} * \mathrm{CaF}-0.00542(\mathrm{CaF} * \mathrm{AlF})^{1.5} \\
& -\frac{7.93 * \mathrm{AlO}}{1+0.0936 * \mathrm{AlO}-0.0017 * \mathrm{AlO}^{2}-0.0023 * \mathrm{AlO} * \mathrm{AlF}} \\
& -\frac{8.90 * \mathrm{LiF}}{1+0.0047 * \mathrm{LiF}+0.0010 * \mathrm{AlF}^{2}}-3.95 \mathrm{MgF}-3.95 \mathrm{KF}, \\
& T c r=T c r s+\Delta 1, \\
& \Delta 1=T c e-T c r
\end{aligned}
$$

where Tcrs, Tcr, and Tce are liquidus in degree Celsius $\left({ }^{\circ} \mathrm{C}\right)$, by Solheim empirical equation, by equation with correction, and by measurement, respectively; $\mathrm{CaF}, \mathrm{AlO}, \mathrm{MgF}, \mathrm{KF}, \mathrm{LiF}$, and $\mathrm{AlF}$ are the concentrations of $\mathrm{CaF}_{2}, \mathrm{Al}_{2} \mathrm{O}_{3}, \mathrm{MgF}_{2}, \mathrm{KF}, \mathrm{LiF}$, and $\mathrm{AlF}_{3}$ in weight percent, respectively; $\Delta 1$ is revised item calculated by measured data on site.

Because many components in electrolyte vary slowly in a long time for many aluminum plants, we supposed they are constant in analysis cycle, such as $\mathrm{CaF}=5.2, \mathrm{MgF}=1.2$, $\mathrm{KF}=0.4$, and $\mathrm{LiF}=0.8$. If the liquidus of the electrolyte is preset, the required concentration of $\mathrm{AlF}_{3}$ can be calculated from analyzed data using (8), (9), and (10). If the objective temperature is $952^{\circ} \mathrm{C}$ and superheat is $10^{\circ} \mathrm{C}$, the concentration of $\mathrm{AlF}_{3}$ is $37.1 \%$ (wt) for the cells we need to control. The amount of $\mathrm{AlF}_{3}$ addition can be calculated by use of (2) to (7).

3.2. The Set Voltage. The system controls the temperature and the concentration of $\mathrm{AlF}_{3}$ by adjusting the cell average voltage and fluoride addition. In temperature model (3),
Tc can be measured every day, $\Delta A$ can be set to be the required value [11], $\Delta F$ is solved by (8), and Err is got by the difference between last measurement and the corresponding calculation. So the set voltage can only depend on the target temperature. In the special case the temperature is decided by the cell voltage.

\section{Correction for the Models}

4.1. The Error Items in the Models. In certain periods the external condition does not have a big change, so that both models can satisfy the control of the cells by only revising the error items, which are renewed at least every week. For the temperature model, the differences between the measured temperature and the target temperature were used to revise the error item. For the liquidus model, the difference between the measured liquidus temperature and the calculated liquidus temperature was used to revise the error item by (10). The liquidus temperature was measured at least once every week.

4.2. The Coefficients in the Models. As the cell age increases or the external condition changes, the error items will jump up and down, which means the models built with the historic data are not suitable anymore, so the coefficients of the models should be revised with the new data. This case is usually caused by two conditions, one is the change of material property, such as anode, alumina and fluoride, the other is the cell has used too long. Here we use the average square difference as follows to renew the coefficients of the models:

$$
\begin{gathered}
E_{1 q}=\frac{1}{N} \sum_{n=1}^{N}\left(S p_{y n}-S p_{r n}\right)^{2}, \\
E_{\text {temp }}=\frac{1}{N} \sum_{n=1}^{N}\left(T e_{y n}-T e_{r n}\right)^{2},
\end{gathered}
$$

where $E_{l q}$ is the average square difference for the error item of liquidus model, $E_{\text {temp }}$ is the average square difference for the error item of temperature model, $S p_{y n}$ and $S p_{r n}$ are the calculated superheat from the model and the measured one, respectively, $T e_{y n}$ and $T e_{r n}$ are the calculated temperatures from the model and the measured one, respectively, and $N$ is the days to be used to calculate the error.

Usually, if $N=30, E_{\text {temp }}>9$, or $E_{l q}+E_{\text {temp }}>15$, the coefficients of the models should be revised. This usually occurs when a batch of feedings was used up or the electrical current changes greatly.

\section{Application of the System}

5.1. The Construct of Control System. According to the description above, the control system mainly includes decision of objective temperature and superheat, calculation of control amount by the building models, and the correction of the model online. The schedule is shown in Figure 1. The max adjusted voltage is $30 \mathrm{mv}$ and the fluoride addition $100 \mathrm{~kg}$; that 


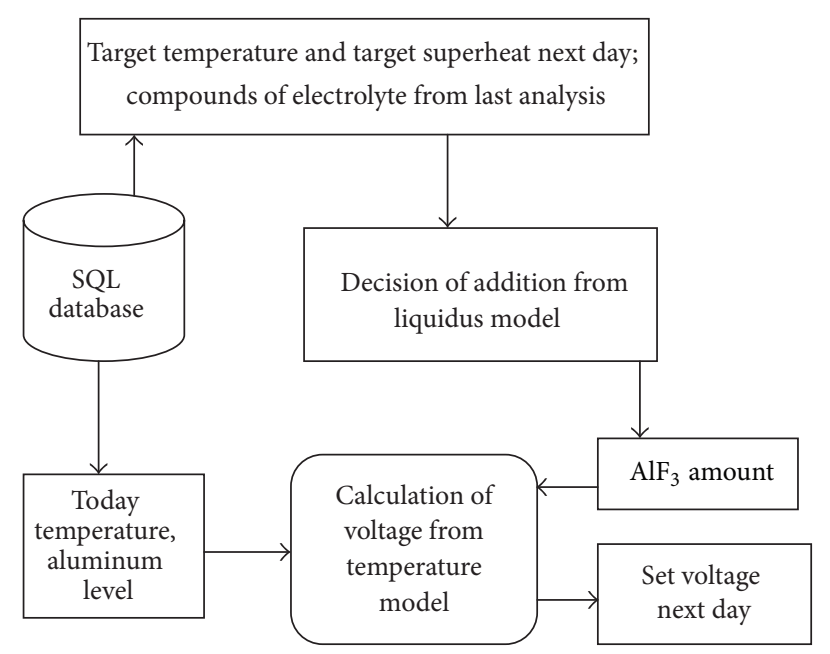

Figure 1: The calculation schedule for cell voltage and fluoride addition amount.

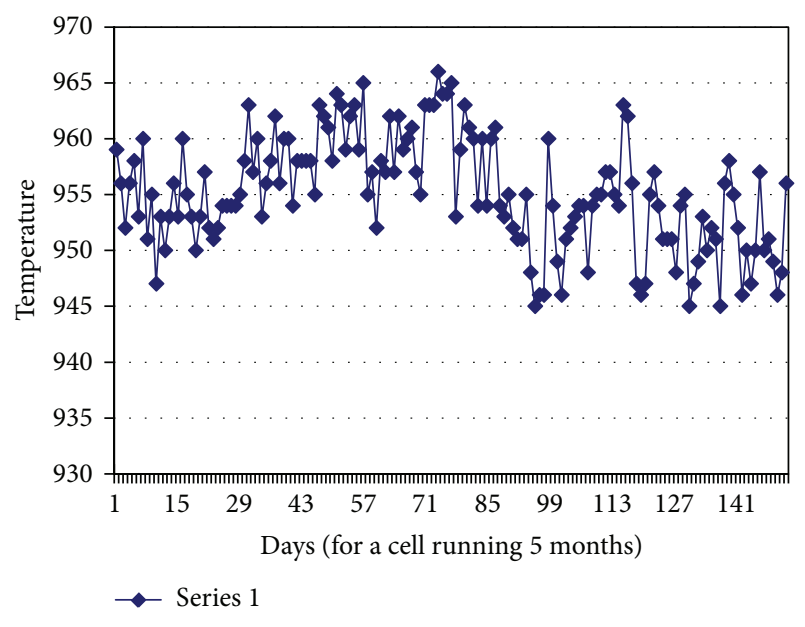

FIGURE 2: Temperature change (measured once each day).

is, if the set voltage is larger than $30 \mathrm{mv}$, it is set to $30 \mathrm{mv}$; if computed value of the fluoride addition is larger than $100 \mathrm{~kg}$, it equals $100 \mathrm{~kg}$. This system worked in the upper computers, which integrated with the diagnosis system [12].

5.2. The Results of the Control. The system has been working in an aluminum company in West China for 2 years. The four cells were indicated by plant manager for test. Figure 2 shows the temperature changes for one cell. The average temperature is 951 centigrade degree. Figure 3 shows the concentration of $\mathrm{AlF}_{3}$ changes with time. All data in the figures come from the economic reports in the factory.

It is shown in Figures 2 and 3 that the temperature and the concentration of $\mathrm{AlF}_{3}$ can be well controlled by the models developed by this paper. Figure 4 showed that the energy consumption decreases more than $1000 \mathrm{kwHr} / \mathrm{tAl}$ in 12 months.

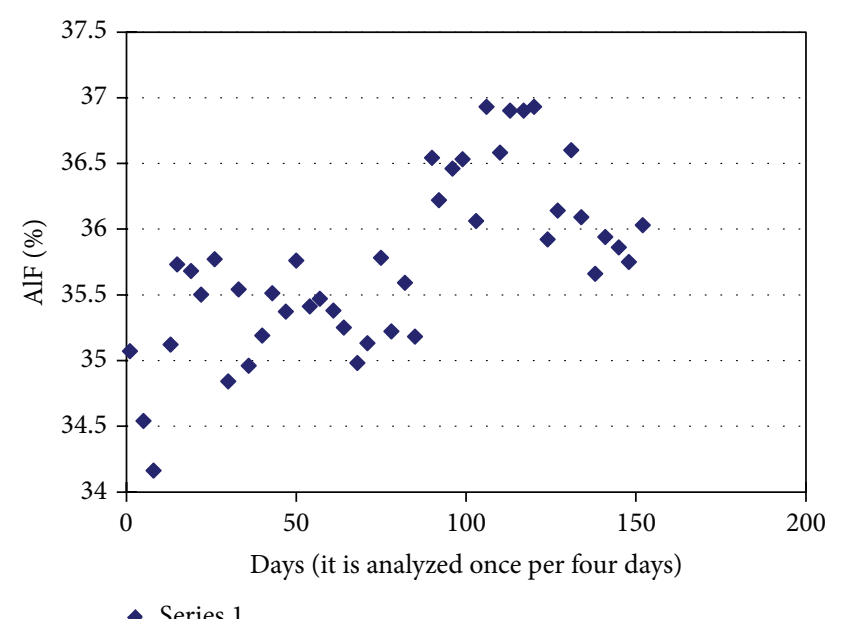

- Series 1

Figure 3: The change of concentration of $\mathrm{AlF}_{3}$.

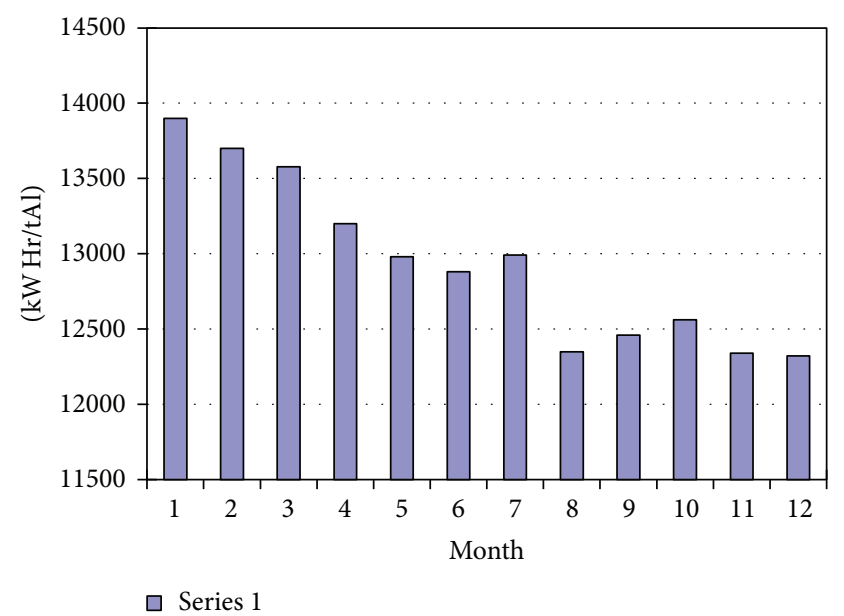

FIGURE 4: Energy consumption change for the system running 12 months (all four test cells).

\section{Conclusions}

The model of temperature and the concentration of $\mathrm{AlF}_{3}$ were built by use of historic data sampled previously, and the error can be corrected online in order to keep the system stable and running with good results. The algorithm of the set voltage and the amount of $\mathrm{AlF}_{3}$ addition was given in combination with the industrial aluminum production, and the control system was constructed and applied in an aluminum plant. The application showed that the temperature and the concentration of $\mathrm{AlF}_{3}$ can be well controlled and the energy consumption decreases more than $1000 \mathrm{kwHr} / \mathrm{tAl}$ within 12 months by the method described here.

There are still some problems in the control process; for example, the accuracy of the measured data has much effect on the control results. Because of the correction of models based on the measurement of temperature and the analysis of the concentration of $\mathrm{AlF}_{3}$, the error of measurement causes the faults of calculation from the models. Several times we observed the bad control is much related to the 
measurements, so that precise measurement is the key to promise the control effect by this method. If the measured data is incorrect, we must use a filter to treat the data, which will be discussed in other papers. The other problem which caused the temperature and the concentration of $\mathrm{AlF}_{3}$ away from the set value is that the anode change operation is not standard arrangement. It is considered that precise measurement and standard change anode is the base of good control system. On the other hand, the calculated model is different for each cell, because of the different historic data, which caused a large amount of calculation in running process.

\section{Conflict of Interests}

The authors declare that there is no conflict of interests regarding the publication of this paper.

\section{Acknowledgments}

The authors thank the Baotou Hope Aluminum Company for providing convenience for the application of the control system. This work is supported by National Natural Science Foundation of China (Project 51174007).

\section{References}

[1] Q. Zhuxian, Prebake Aluminum Production, Metallurgy Press, Beijing, China, 3rd edition, 2005.

[2] L. Yexiang and L. Jie, Modern Aluminum Electrolysis, Metallurgy Press, Beijing, China, 2008.

[3] Simões, Thiago, Martins, João Alberto et al., "The impact of bath ratio control improvements on current efficiency increase," TMS Light Metals, pp. 361-365, 2008.

[4] H. Yong-bo, Q. Xiang-dong, and Z. Jie-min, "Coupled heat/mass-balance model for analyzing correlation between excess $\mathrm{AlF}_{3}$ concentration and aluminum electrolyte temperature," Transactions of Nonferrous Metals Society of China, vol. 19, no. 3, pp. 724-729, 2009.

[5] Z. Shuiping, L. Jinhong, and R. Bijun, "Adaptive fuzzy control system of $300 \mathrm{kA}$ aluminum production cell," TMS Light Metals, pp. 559-563, 2007.

[6] V. Yurkov, V. Mann, T. Piskazhova, K. Nikandrov, and O. Trebukh, "Dynamic control of the cryolite ratio and the bath temperature of aluminium reduction cell," TMS Light Metals, pp. 383-388, 2002.

[7] L. Jie, W. Qianpu, X. Jin et al., "Intelligent fuzzy control system for aluminum reduction cells," Chinese Journal of Nonferrous Metals, vol. 8, no. 3, pp. 557-562, 1998.

[8] C. Xiangtao, L. Jie, Z. Wengen et al., "The development and application of data warehouse and data mining in aluminum electrolysis control systems," TMS Light Metals, pp. 515-519, 2006.

[9] S. Asbjorn, R. Sverre, S. Egil, S. Lisbet, S. Asmund, and T. Trond, "Liquidus temperatures for primary crystallization of cryolite in molten salt systems of interest for aluminum electrolysis," Metallurgical and Materials Transactions B: Process Metallurgy and Materials Processing Science, vol. 27, no. 5, pp. 739-744, 1996.
[10] Z. Shuiping and L. Jinhong, "Fruzzy predictive control system of cryolite ratio for prebake aluminum production cells," in Proceedings of 7th World Congress on Intelligent Control and Automation, pp. 1229-1233, Zhongqing, China, 2008.

[11] Z. Shuiping and L. Yexiang, "Mathematical model for continuous detection of current efficiency in aluminum production," Transactions of Nonferrous Metals Society of China, vol. 8, no. 4, pp. 686-687, 1998.

[12] S. Zeng, L. Cui, and J. Li, "Diagnosis system for alumina reduction based on BP neural network," Journal of Computers, vol. 7, no. 4, pp. 929-933, 2012. 

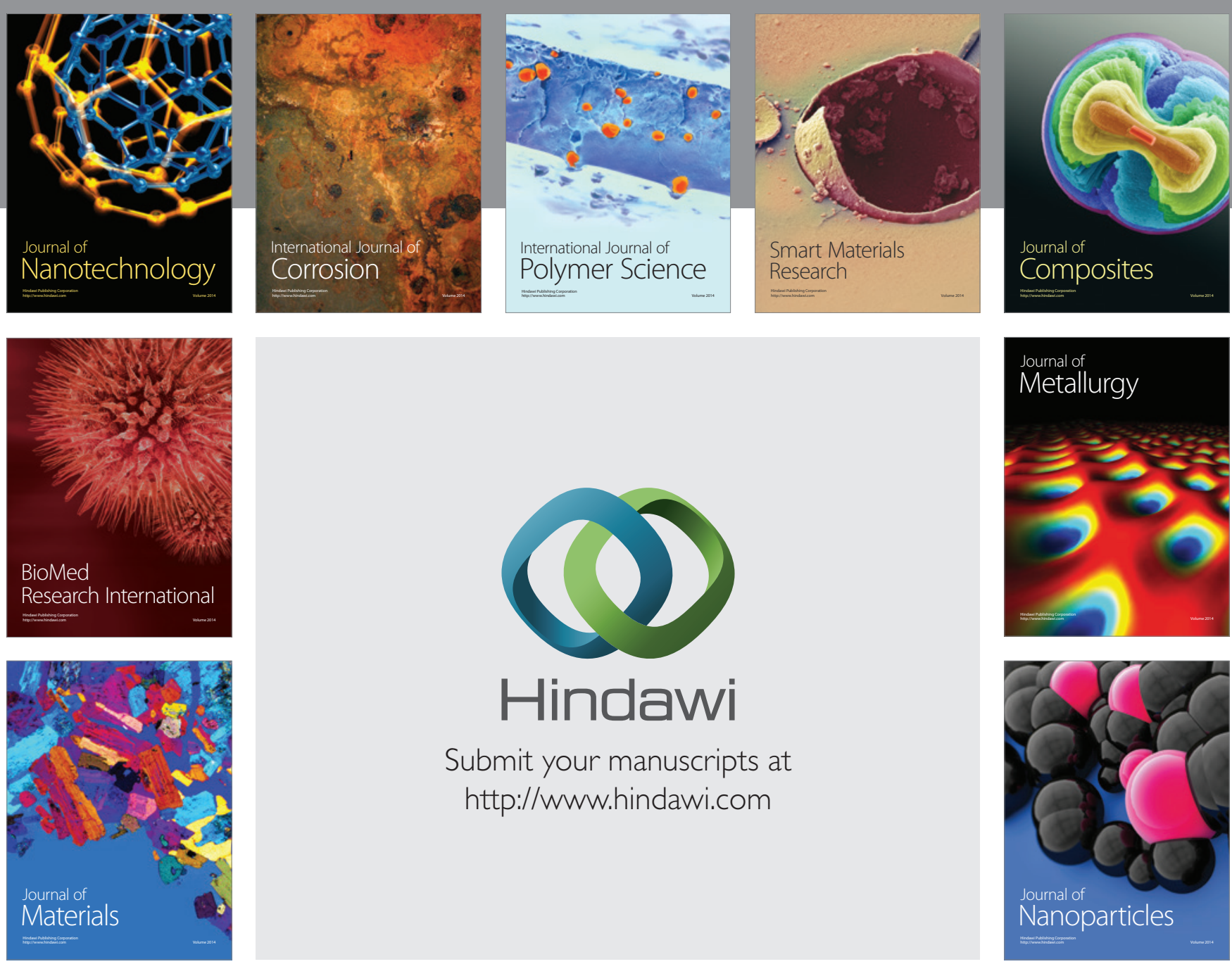

Submit your manuscripts at http://www.hindawi.com
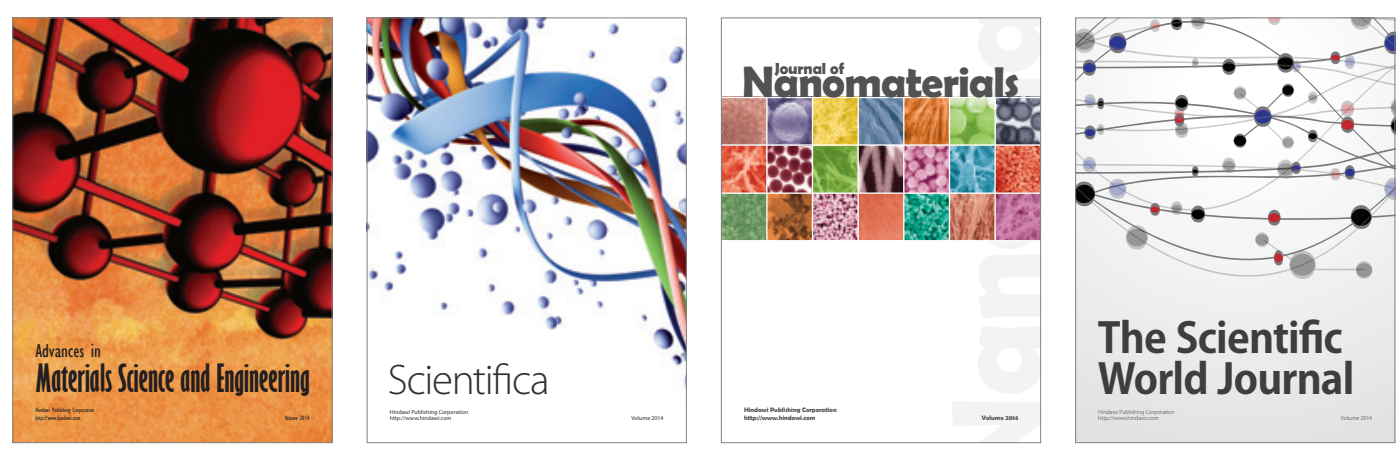

\section{The Scientific World Journal}
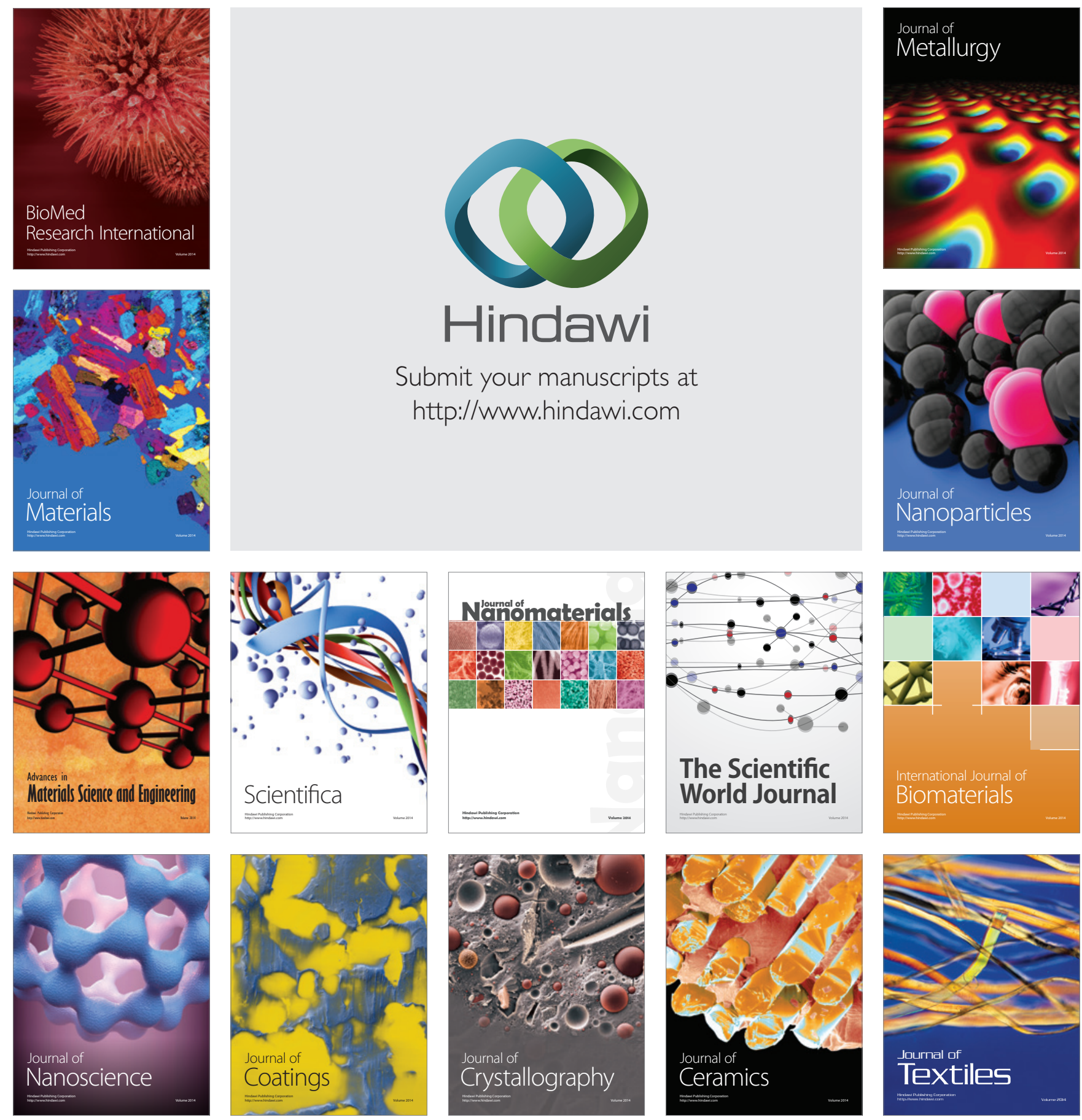